\title{
Effects of probiotics in patients with diabetes mellitus type 2: study protocol for a randomized, double-blind, placebo-controlled trial
}

\author{
Majed S Alokail ${ }^{1,2,7^{*}}$, Shaun Sabico ${ }^{1,6+}$, Yousef Al-Saleh ${ }^{3}$, Nasser M Al-Daghri ${ }^{1,2}$, Khalid M Alkharfy ${ }^{1,4}$, \\ Paul M Vanhoutte ${ }^{1,5}$ and Philip G McTernan ${ }^{6}$
}

\begin{abstract}
Background: Low grade chronic inflammation is observed in patients with type 2 diabetes mellitus (T2DM). Endotoxin derived from gut bacteria may act as a potent inflammatory stimulant. Probiotics, which are believed to contain health promoting live microorganisms, may influence circulating endotoxin levels. Ingestion of live probiotic cultures may alter gut microbiota in a beneficial manner to reduce inflammation; no information is available whether or not they do so in patients with T2DM. Therefore, the aim of this study is to characterize the beneficial effects of probiotics on circulating endotoxin levels and other biomarkers related to systemic low-grade inflammation in patients with T2DM.
\end{abstract}

Methods: One hundred and twenty consenting adult Saudi T2DM patients (naïve or newly diagnosed and without co-morbidities) will be enrolled in this clinical trial and randomized to receive daily placebo or probiotics (Ecologic ${ }^{\oplus}$ Barrier) for 26 weeks in a double-blind manner. Inflammatory and metabolic markers will be measured and fecal samples analyzed. Measurements/samples will be obtained at baseline and after 4, 8, 12/13 and 26 weeks of treatment.

Discussion: It is expected that the probiotic product will induce beneficial changes in gut microbiota, reduce the systemic inflammatory state through altering systemic endotoxin levels and, as such, reduce the systemic inflammatory response observed in T2DM subjects.

Trial registration: ClinicalTrials.gov Identifier: NCT01765517

Keywords: Type 2 diabetes mellitus, Endotoxin, Microbiota, Probiotics

\section{Background}

The human gastrointestinal tract contains bacteria, archaea and eukarya. In particular, bacteria living in the gut achieve the highest cell density recorded for any ecosystem [1]. However, gut microbiota does not exist independently and interacts at several levels in the functions of the body [1]. Specifically, gut microbiota can influence intestinal peristalsis [2], but also affects the expression of various host genes that regulate nutrient uptake, metabolism, angiogenesis, mucosal barrier function, the

\footnotetext{
* Correspondence: msa85@yahoo.co.uk

${ }^{\dagger}$ Equal contributors

${ }^{1}$ Biomarkers Research Program, King Saud University, Riyadh 11451, Saudi Arabia

${ }^{2}$ Center of Excellence in Biotechnology Research, King Saud University,

Riyadh 11451, Saudi Arabia

Full list of author information is available at the end of the article
}

development of the enteric nervous system and maturation of mucosal immunity [3]. Interestingly it appears that fragments of Gram negative bacteria derived from the gut (endotoxin) can cross the intestinal mucosa to enter the circulation, and may represent an important mediator of low-grade systemic inflammation influenced by the host's own gut microbiota and metabolic state. Previous studies have shown that low levels of endotoxin can enter the blood circulatory system, which may stimulate an innate immune response from adipose tissue, liver and skeletal muscle, leading to production of pro-inflammatory cytokines [4-9]. Endotoxin has been shown to act as a mediator of inflammation in liver disease $[10,11]$, whilst cross-sectional and longitudinal studies have indicated that a reduction in circulating 
endotoxin leads to a reduction in inflammatory cytokines and inflammatory response [12-15]. Furthermore, abnormal alterations in diet have a profound influence on human endotoxin circulation, but more so for patients with type 2 diabetes mellitus (T2DM) [16]. It makes sense that manipulation of diet to normalize the gut microflora and metabolic functions has been the mainstay management for most chronic diseases. In fact, a well-controlled diet is a major nonpharmacologic option for the prevention of T2DM $[17,18]$. As such, influencing the gut microbiota with the addition of probiotics may affect the systemic effects of endotoxin and represent a new and enhanced mechanism to treat low-grade chronic inflammatory conditions, such as seen in T2DM. The present study proposes to test the hypothesis that probiotics will alter the gut microbiota sufficiently to reduce systemic endotoxins and the resulting inflammation in subjects with T2DM, thus offering an additional intervention to treat these patients. To achieve this, 120 consenting adult Saudi T2DM patients without co-morbidities will be enrolled in this clinical trial and randomized to receive twice-daily placebo or probiotics for 26 weeks in a double-blind manner. Glycemic and inflammatory markers will be measured at baseline and at weeks 8 , 12 and 26 . The study will specifically explore the effects of probiotics on endotoxin levels in patients with DMT2 and relate them to the circulating levels of inflammatory cytokines.

\section{Methods}

\section{Design}

In this 26-week, single-center, double-blind, randomized, placebo-controlled study, 60 patients with T2DM will be treated with probiotics and 60 will be treated with placebo. Interventions will be performed at weeks $0,4,8,12$ and 26 in all subjects. Patients allocated to the probiotics group will receive two sachets with $2 \mathrm{~g}$ freeze-dried powder of the probiotic mixture Ecologic Barrier daily (Winclove probiotics, the Netherlands). Ecologic ${ }^{\circ}$ Barrier $\left(2.5 \times 10^{9} \mathrm{cfu} / \mathrm{gram}\right)$ contains the following bacterial strains: Bifidobacterium bifidum W23, Bifidobacterium lactis W52, Lactobacillus acidophilus W37, Lactobacillus brevis W63, Lactobacillus casei W56, Lactobacillus salivarius W24, Lactococcus lactis W19 and Lactococcus lactis W58. Participants in the placebo group will receive the placebo consisting of the carrier of the probiotic product, that is maize starch and maltodextrins. The placebo is indistinguishable in color, smell and taste from the probiotic sachets, but contains no bacteria.

\section{Recruitment of patients}

Recruitment of patients to this study will be made possible by collaboration with primary care centers throughout Riyadh and the Biomarkers Research Program, College of Science, King Saud University.

\section{Ethical approval}

The study protocol has been approved by the ethics committee of the College of Science, King Saud University, Riyadh, Saudi Arabia.

\section{Inclusion criteria}

- Stable and well controlled T2DM (glycosylated hemoglobin $(\mathrm{HbA} 1 \mathrm{c})<7.5 \%$ and no change in oral anti-diabetic medications during the last 6 months)

- Age 20 to 75 years

- Provision of written informed consent

\section{Exclusion criteria}

- Chronic gastrointestinal disease (except irritable bowel syndrome)

- Systemic antibiotics within 6 weeks before inclusion

- Use of probiotics within 3 months before inclusion

- Regular intake of insulin or insulin analogs, antibiotics or probiotics, antacids, H2-receptor blockers, proton pump inhibitors, loperamide, cholestryramine, $\omega 3$-unsaturated fatty acid supplements, fibrates, corticosteroids or sex steroids

- Daily alcohol consumption > $30 \mathrm{~g}$

- Significant immunodeficiency

- Known cardiac valvular disease

- Breast-feeding or pregnancy

- Non-Arab ethnicity

- Participation in another clinical trial within the last 6 months

- Legal incapability or mental incapacity to give consent.

\section{Allocation to treatment}

After confirmation of eligibility and obtaining written informed consent, the patients will be given a unique subject number by the research nurse. The randomization (stratified for gender) will be performed by the probiotic company and the patients and clinicians at the primary care center will be blinded to the treatment received. The eligible patients will be allocated (1:1) to treatment for 26 weeks with either the probiotics supplement or placebo. Subjects will be instructed to:

- Ingest one sachet before breakfast and one sachet before going to bed, by mixing the powder in lukewarm water and drinking it.

- The sachets will be stored at room temperature. 


\section{Data handling and record keeping}

Case report forms (CRF) will be used to record data for all participants, and will be completed by the research nurse, who will also enter the data into an electronic database.

\section{Study schedule and location}

After inclusion, all further treatments will be managed at the primary care center where the subject was recruited (see Table 1 for scheduled visits). A research nurse and a research dietician will be responsible for all contacts with patients. Doctors associated with the research team will be available if problems arise.

\section{Acquisition of clinical data and assessment of compliance}

- Medical history, including the presence of chronic diseases, regular medication, smoking and alcohol habits, will be recorded before inclusion.

- Nutritional habits will be assessed using a standardized 14-day recall questionnaire, which will be discussed with a dietician.

- Changes in medication during the study period will be recorded

- Anthropometric measurements will be made using standardized methods. Height will be measured at the start of treatment. Weight (in light clothing without shoes or items in pockets), waist circumference (measured as a horizontal plane at the level of the umbilicus) and hip circumference

Table 1 Schedule of visits

\begin{tabular}{|c|c|c|c|c|c|c|c|c|}
\hline & \multirow{2}{*}{$\begin{array}{l}\text { Pre- } \\
\text { screening }\end{array}$} & \multirow[t]{2}{*}{ Screening } & \multirow[t]{2}{*}{ Inclusion } & \multicolumn{5}{|c|}{ Week } \\
\hline & & & & 0 & 4 & 8 & 12 & 26 \\
\hline $\begin{array}{l}\text { Patient attends } \\
\text { the health clinic }\end{array}$ & & $x$ & & $x$ & & $x$ & $x$ & $x$ \\
\hline Telephone review & & & & & X & & & \\
\hline $\begin{array}{l}\text { Identification of } \\
\text { eligible subjects }\end{array}$ & $x$ & & & & & & & \\
\hline Check eligibility & & $x$ & & & & & & \\
\hline $\begin{array}{l}\text { Obtain informed } \\
\text { consent }\end{array}$ & & & $x$ & & & & & \\
\hline Blood sampling & & & & $x$ & & $x$ & & $x$ \\
\hline Stool sampling & & & & $x$ & & $x$ & & $x$ \\
\hline $\begin{array}{l}\text { Provision of test } \\
\text { product }\end{array}$ & & & & $x$ & & $x$ & $x$ & \\
\hline $\begin{array}{l}\text { Return of } \\
\text { previously } \\
\text { provided test } \\
\text { product }\end{array}$ & & & & & & $x$ & $x$ & $x$ \\
\hline $\begin{array}{l}\text { Assessment of } \\
\text { compliance and } \\
\text { adverse events }\end{array}$ & & & & & $x$ & $x$ & $x$ & $x$ \\
\hline
\end{tabular}

(measured as a horizontal plane at the level of the trochanter major) will be measured at the start and end of the treatment.

- Liver ultrasonography will be performed either at screening or at the start of treatment to determine the presence or absence of a bright liver indicative of steatosis. Patients with fatty liver and liver transaminases $>1.5 \times$ the upper limit of normal will be offered referral to a hepatologist.

- Compliance will be monitored at weeks 4, 8, 12 and 26. Patients will bring their previously received sachets to the primary care center to calculate the mean number of sachets used per day.

\section{Acquisition of routine biochemical data and biological samples}

- Blood samples obtained will be analyzed at the Biomarkers Research Program to measure glucose, HbA1c, insulin, C-peptide, total cholesterol, highdensity lipoprotein cholesterol, low-density lipoprotein cholesterol, triglycerides, alanine aminotransferase and aspartate aminotransferase levels.

- Fasting blood samples will be collected at weeks 0,8 and 26. Peripheral venous blood will be drawn into pyrogen-free tubes without any anticoagulant. The tubes will be immediately placed in ice, allowed to coagulate, and centrifuged ( $2500 \times g$ for 10 minutes at $4^{\circ} \mathrm{C}$ ) within 2 hours of collection. Serum samples will be stored at $-80^{\circ} \mathrm{C}$ until use. At least two $2-\mathrm{mL}$ serum samples will be collected at each time-point.

- Stool samples will be obtained at the same time points as blood samples and stored in a plastic sealable bag to be handed over to the clinic. Once at the clinic, the samples will be divided, flash frozen, and stored at $-80^{\circ} \mathrm{C}$. Changes in gut microbiota will be profiled using signature-tagged sequencing (pyrosequencing) of amplified $16 \mathrm{~S}$ rRNA genes followed by automated bioinformatics analysis. Targeted RT-PCR will also be used to examine bacterial species such as Enterobacteria and Bifdobacteria relative to the universal bacterial primer set. Pyrosequencing and RT-PCR will be performed in a sub-cohort $(\mathrm{n}=15)$ of patients considering the final systemic findings. Samples will be retained for subsequent studies.

\section{Subject withdrawal}

Subjects may withdraw from the trial at any time at their own request, or they may be withdrawn at any time at the discretion of the investigator for safety, behavioral or administrative reasons. The subjects will also be withdrawn from the study in case of: 
- Treatment with systemic antibiotics for more than 1 week during weeks 0 to 22

- Any use of systemic antibiotics during weeks 22 to 26

\section{Patient safety}

\section{Adverse events}

Adverse events are undesirable signs or symptoms that occur during the study and may or may not be causally related to the treatment. All adverse events considered possibly, probably or definitely related to the tested product will be recorded on CRFs.

\section{Serious adverse events}

Serious adverse events are defined as events that are fatal, life-threatening, disabling, incapacitating or result in hospitalization or prolonged hospital stay, or result in malformation. All will be recorded in the CRF, whether they are related to the test product or not. According to previous studies [9], probiotics are safe, and any serious adverse event that might be possibly, probably or definitely related to the test product will be regarded as unexpected. All unexpected serious adverse events will be reported immediately to the Medicines and Healthcare products Regulatory Agency. Any serious adverse event that might be related to the tested product will immediately lead to discontinuation of the test product.

\section{Ethical and regulatory aspects}

The study will be performed in accordance with the protocol and the ethical principles that have their origin in the Declaration of Helsinki as well as with the International Council for Harmonization Guidance on Good Clinical Practice. These documents state that the informed consent of subjects is an essential precondition for participation in the clinical study. The study will commence only after obtaining approval from the local ethical review board of the College of Medicine Research Center, King Saud University.

\section{Statistical aspects \\ Sample size}

Preliminary data indicate that serum endotoxin levels in T2DM patients are two to three times higher than in control subjects. We hypothesize that treatment with probiotics will reduce mean endotoxin levels by 25 to $30 \%$, while no change will be seen in the placebo group. To obtain $80 \%$ power to demonstrate a statistically significant difference (two-sided $P$-value $=0.05)$ between the two treatments, 100 patients must be treated (50 patients per group). As we expect a dropout rate of $15 \%$, we will include 120 patients in the study.
The sample size was calculated based on the estimated mean change during treatment ( $\Delta$-values) and corresponding standard deviation (SD) of the change. Since we have no repeated measurements of endotoxin in the same individuals, we need to estimate the SD for the change. Assuming that the correlation between 1 and 2 yields a measurement of 0.70 , the SD for the $\Delta$-value is $78 \%$ of the SD of separate measurements (Table 2). Table 3 shows the estimated sample size according to various assumptions of treatment effect and correlation between one and two measurements.

\section{Plan for data analysis}

As this trial is designed to assess the physiological effects rather than support clinical indications for treatment with probiotics in T2DM, we plan to perform per protocol analyses. Only subjects treated with at least $80 \%$ of the planned doses for at least $80 \%$ of the time will be considered as treated per protocol.

Raw data will be entered into statistical software (SPSS version 16.5, Chicago, IL, USA). Preparation of the dataset will be done prior to analysis. Descriptive statistics will be performed, and frequencies will be presented as a percentage. Continuous variables will be presented as mean $\pm \mathrm{SD}$. Variables exhibiting nonGaussian variables will be transformed prior to analysis. Repeated measures analysis of co-variance will be used to compare groups, which will represent a combination of analysis of variance and linear regression. Confounding and fixed variables such as age and gender, as well as body mass index, will be taken if proper matching has not been achieved prior to repeated measures. Post hoc Banjamini-Hohberg corrections will be done for multiple comparisons. For comparison of two groups, an independent $t$-test will be applied for continuous variables and Mann-Whitney for non-continuous variables. Analysis of adverse events (if any) will be performed using Chi-Square test and Fisher's exact test following assumptions of randomness, independence and size. Significance will be set at $P<$ 0.05 .

\section{Limitations}

The investigators are aware that systemic inflammatory markers may not change during the clinical trial; however, this would not preclude the study as we understand that probiotics do affect gut microbiota and that this may have beneficial effects as noted in previous rodent and human studies. Furthermore, probiotics have been previously shown to affect lipopolysaccharide levels and this may still have long-term beneficial effects which may have a trend effect on inflammatory or insulin resistance markers and thus may indicate that a longer 
Table 2 Standard deviation and correlation between measures

\begin{tabular}{lll}
\hline $\begin{array}{l}\text { SD for each } \\
\text { measurement }\end{array}$ & $\begin{array}{l}\text { Correlation between } \\
\text { measures }\end{array}$ & $\begin{array}{l}\text { SD of the } \\
\Delta \text {-value }\end{array}$ \\
\hline 1 & 0.60 & 0.89 \\
1 & 0.65 & 0.84 \\
1 & 0.70 & 0.78 \\
1 & 0.75 & 0.71 \\
1 & 0.80 & 0.63 \\
\hline
\end{tabular}

$\Delta$-value, mean change; SD, standard deviation.

term treatment is required. In either case, to examine the effects of a probiotic in a clearly designed clinical trial will provide new understanding and warrants investigation.

\section{Discussion}

Many different probiotic strains have been identified and the effects of these bacteria, either given in monoculture or as a cocktail of various strains, have been subject to increasing scientific evaluation in recent years. Probiotic bacteria (with the best documented strains being species of Lactobacillus or Bifidobacterium) inhibit the growth of pathogenic bacteria by acidifying the gut lumen, competing for nutrients, and producing antimicrobial substances $[19,20]$. Furthermore, they adhere to the gastrointestinal mucosa and are thought to prevent bacterial translocation from the gut [21]. The strongest evidence for the use of probiotics has been in the management of diarrhea [22]. Data extrapolated from a large number of studies, including systemic reviews [23-26], meta-analyses [27-30], open-label studies [31,32] and multicenter trials testing the efficacy of probiotics in preventing diarrhea, concluded that, in addition to having a good safety profile, probiotics significantly reduced the duration and frequency of acute diarrhea [33]. In addition, trials have documented favorable effects of probiotics in other gastrointestinal diseases (for example, irritable bowel syndrome, pouchitis and necrotizing enterocolitis in premature infants). Studies in obesity have also shown altered gut microbial compositions in human subjects and in mice [34-43]. The guts of obese human subjects appear to have reduced numbers of Bacteroidetes and increased numbers of Firmicutes compared with lean people [36]. During a 1-year intervention trial in obese humans on a hypocaloric diet, an increased proportion of fecal Bacteroidetes was observed to parallel weight loss [36]. Diet-induced obesity in animal models may also lead to increased Mollicutes

Table 3 Sample size determination for endotoxin

\begin{tabular}{|c|c|c|c|c|c|}
\hline Endotoxin baseline (U/L) & $\begin{array}{l}\text { Difference in } \\
\Delta \text {-value (probiotics } \\
\text {-placebo) }\end{array}$ & $\begin{array}{l}\text { SD for change } \\
\text { (common for } \\
\text { both treatments) }\end{array}$ & $\begin{array}{l}\text { Correlation for } \\
1 \text { and } 2 \\
\text { measurements }\end{array}$ & $\begin{array}{l}\text { Sample size (total) } \\
\text { 2-tailed a: } 0.05 \text { Power: } 80 \%\end{array}$ & $\begin{array}{l}\text { Sample size (total) } \\
\text { 2-tailed a: } 0.05 \text { Power: } 90 \%\end{array}$ \\
\hline \multirow[t]{20}{*}{$10( \pm 6)$} & -2 & 5.34 & 0.60 & 224 & 298 \\
\hline & -2 & 5.04 & 0.65 & 200 & 266 \\
\hline & -2 & 4.68 & 0.70 & 176 & 236 \\
\hline & -2 & 4.26 & 0.75 & 148 & 198 \\
\hline & -2 & 3.78 & 0.80 & 116 & 154 \\
\hline & -2.5 & 5.34 & 0.60 & 144 & 192 \\
\hline & -2.5 & 5.04 & 0.65 & 128 & 172 \\
\hline & -2.5 & 4.68 & 0.70 & 114 & 152 \\
\hline & -2.5 & 4.26 & 0.75 & 96 & 128 \\
\hline & -2.5 & 3.78 & 0.80 & 76 & 100 \\
\hline & -3 & 5.34 & 0.60 & 100 & 134 \\
\hline & -3 & 5.04 & 0.65 & 90 & 120 \\
\hline & -3 & 4.68 & 0.70 & 80 & 106 \\
\hline & -3 & 4.26 & 0.75 & 68 & 90 \\
\hline & -3 & 3.78 & 0.80 & 54 & 70 \\
\hline & -4 & 5.34 & 0.60 & 58 & 76 \\
\hline & -4 & 5.04 & 0.65 & 52 & 68 \\
\hline & -4 & 4.68 & 0.70 & 46 & 62 \\
\hline & -4 & 4.26 & 0.75 & 40 & 52 \\
\hline & -4 & 3.78 & 0.80 & 32 & 40 \\
\hline
\end{tabular}


(a class of Firmicutes), a response which appears to be reversible with dietary manipulation aimed at limiting weight gain [37]. The finding that the microbial composition is modulated by dietary modification suggests that differences in the gut composition between obese and lean individuals are related to dietary factors independent of obesity $[15,44]$. However, not all studies have shown beneficial effects of probiotics, and thus caution should be taken in terms of the dosage and strains to be used, as these may have important ramifications on the effects observed. In this study, a combination of probiotic strains will be used, as there are suggestions that multispecies products are more effective than single strain products $[45,46]$. The strains were selected for this product based on different in vitro screening criteria. Among the criteria were the inhibition of cytokine-induced barrier dysfunction of the epithelial cell line Caco-2, the capacity to induce expression of interleukin-10 [47] (as this antiinflammatory cytokine has a protective function on the epithelial barrier [48]), the ability to break down lipopolysaccharides and the inhibition of mast cell activation [49].

Taken together, the current evidence appears to support a role for the gut microbiota in the pathogenesis of diet-induced obesity and related metabolic disorders, which may be reversible with dietary and/or gut microbiota manipulation [50]. As the gut microbiota is the main source of endotoxin, treatment with probiotics may influence the circulating levels of endotoxin by altering the microbiota composition. To date, relatively few studies have examined the effects of endotoxin in metabolic diseases using probiotics. To the best of our knowledge, this hypothesis has not been tested except in a small study of patients with cirrhosis in which a $25 \%$ reduction in endotoxin was reported [1]. However, animal studies have revealed that treatment with probiotics may be beneficial in insulin-resistant states [2,37]. Probiotics also delay the onset of glucose intolerance in high-fructose-fed rats [3]. To expand on these earlier findings, the present study will explore the potential beneficial effects of probiotics on circulating endotoxin levels and other markers for systemic low-grade inflammation in patients with T2DM.

In summary, we expect that our findings will demonstrate that probiotics alter gut microbiota in T2DM and that, in theory, the alterations will be metabolically favorable with continued probiotic use. Since the efficacy of probiotics is directly linked to the type of strain, we will also be able to identify which strains used in the intervention are most beneficial for patients with T2DM. Further investigations, however, will be needed whether the efficacy of the probiotics used in this study can be extended to prevention levels. Regardless, our study will be the first to address this issue beyond classical inflammatory conditions. This will have a fundamental impact on how we should treat the inflammatory component of T2DM, particularly once the results are verified in a larger cohort of patients.

\section{Trial status}

Estimated enrollment: 120

Study start date: October 2013

Estimated study completion date: October 2015

Estimated primary completion date: October 2015

\section{Abbreviations}

CRF: case report form; HbA1c: glycosylated hemoglobin; RT-PCR: reverse transcription polymerase chain reaction; SD: standard deviation; T2DM: type 2 diabetes mellitus.

\section{Competing interests}

This project is funded by the National Plan for Science and Technology (NPST) (Grant Number: 11-MED2114-02).

\section{Authors' contributions}

SS, MSA, YA and PGM are the principal researchers and conceptualized the study. NMA, KMA and PMV further developed the study design. SS will develop the statistical design. All authors have seen and approved the final version of the protocol.

\section{Acknowledgments}

The authors thank Ms Saskia van Hemert for her intellectual input and Winclove BV (Winclove B.V. Amsterdam, The Netherlands) for the probiotic supplements and placebo.

\section{Author details}

${ }^{1}$ Biomarkers Research Program, King Saud University, Riyadh 11451, Saudi Arabia. ${ }^{2}$ Center of Excellence in Biotechnology Research, King Saud University, Riyadh 11451, Saudi Arabia. ${ }^{3}$ College of Medicine, King Saud University for Health Sciences, Riyadh 11451, Saudi Arabia. ${ }^{4}$ College of Pharmacy, King Saud University, Riyadh 11451, Saudi Arabia. ${ }^{5}$ Department of Pharmacology and Pharmacy, Li Ka Shing Faculty of Medicine, 21 Sassoon Road, Hong Kong, China. ${ }^{6}$ Division of Metabolic and Vascular Health, Warwick Medical School, Clinical Sciences Research Laboratories, University Hospital Coventry and Warwickshire, Walsgrave, Coventry CV2 2DX, United Kingdom. ${ }^{7}$ Biochemistry Department, College of Science, King Saud University, PO Box, 2455, Riyadh 11451, Kingdom of Saudi Arabia.

Received: 16 February 2013 Accepted: 21 June 2013

Published: 4 July 2013

\section{References}

1. Backhed F, Ley RE, Sonnenburg JL, Peterson DA, Gordon Jl: Host-bacterial mutualism in the human intestine. Science 2005, 307:1915-1920.

2. Husebye $E_{1}$ Hellstrom PM, Sundler F, Chen J, Midtvedt T: Influence of microbial species on small intestinal myoelectric activity and transit in germ-free rats. Am J Physiol Gastrointest Liver Physiol 2001, 280:G368-G380

3. O'Hara AM, Shanahan F: The gut flora as a forgotten organ. EMBO Rep 2006, 7:688-693.

4. Al-Attas OS, Al-Daghri NM, Al-Rubeaan K, da Silva NF, Sabico SL, Kumar S, McTernan PG, Harte AL: Changes in endotoxin levels in T2DM subjects on anti-diabetic therapies. Cardiovasc Diabetol 2009, 8:20.

5. Baker AR, Harte AL, Howell N, Pritlove DC, Ranasinghe AM, da Silva NF, Youssef EM, Khunti K, Davies MJ, Bonser RS, Kumar S, Pagano D, McTernan PG: Epicardial adipose tissue as a source of nuclear factorkappaB and c-Jun N-terminal kinase mediated inflammation in patients with coronary artery disease. J Clin Endocrinol Metab 2009, 94:261-267.

6. Brun P, Castagliuolo I, Di Leo V, Buda A, Pinzani M, Palù G, Martines D: Increased intestinal permeability in obese mice: new evidence in the pathogenesis of nonalcoholic steatohepatitis. Am J Physiol Gastrointest Liver Physiol 2007, 292:G518-G525.

7. Creely SJ, McTernan PG, Kusminski CM, Fisher M, Da Silva NF, Khanolkar M, Evans M, Harte AL, Kumar S: Lipopolysaccharide activates an innate 
immune system response in human adipose tissue in obesity and type 2 diabetes. Am J Physiol Endocrinol Metab 2007, 292:E740-E747.

8. Miller M, McTernan P, Harte A, Silva N, Strazzullo P, Alberti K, Kumar S, Cappuccio F: Ethnic and sex differences in circulating endotoxin levels: a novel marker of atherosclerotic and cardiovascular risk in a British multi-ethnic population. Atherosclerosis 2009, 203:494-502.

9. Harte AL, da Silva NF, Creely SJ, McGee KC, Billyard T, Youssef-Elabd EM, Tripathi G, Ashour E, Abdalla MS, Sharada HM, Amin Al, Burt AD, Kumar S, Day CP, McTernan PG: Elevated endotoxin levels in non-alcoholic fatty liver disease. J Inflamm (Lond) 2010, 30:7-15.

10. Soares JB, Pimentel-Nunes $P$, Roncon-Albuquerque R, Leite-Moreira A: The role of lipopolysaccharide/toll-like receptor 4 signaling in chronic liver diseases. Hepatol Int 2010, 4:659-672.

11. Szabo G, Mandrekar P, Petrasek J, Catalano D: The unfolding web of innate immune dysregulation in alcoholic liver injury. Alcohol Clin Exp Res 2011 35:782-786

12. Al-Attas OS, Al-Daghri NM, Alokail MS, Al-Fadda A, Bamakhramah A, Sabico S, Pritlove D, Harte A, Tripathi G, McTernan PG, Kumar S, Chrousos G: Adiposity and insulin resistance correlate with telomere length in middle-aged Arabs: the influence of circulating adiponectin. Eur J Endocrinol 2010, 163:601-607.

13. Al-Attas O, Al-Daghri N, Bamakhramah A, Sabico S, Huang T, McTernan P: Telomere length in relation to insulin resistance, inflammation and obesity among Arab youth. Acta Paediatr 2010, 99:896-899.

14. Dixon AN, Valsamakis G, Hanif MW, Aldaghri N, Field A, Boutsiadis A, Harte AL, McTernan PG, Barnett AH, Kumar S: Effect of the Orlistat on serum endotoxin lipopolysaccharide and adipocytokines in South Asian individuals with impaired glucose tolerance. Int J Clin Pract 2008, 62:1124-1129.

15. Cani PD, Neyrinck AM, Fava F, Knauf C, Burcelin RG, Tuohy KM, Gibson GR, Delzenne NM: Selective increases of bifidobacteria in gut microflora improve high-fat-diet-induced diabetes in mice through a mechanism associated with endotoxaemia. Diabetologia 2007, 50:2374-2383.

16. Harte AL, Varma MC, Tripathi G, McGee KC, Al-Daghri NM, Al-Attas OS, Sabico S, O'Hare JP, Ceriello A, Saravanan P, Kumar S, McTernan PG: High fat intake leads to acute postprandial exposure to circulating endotoxin in type 2 diabetic subjects. Diabetes Care 2012, 35:375-382.

17. Lindstrom J, Neumann A, Sheppard KE, Gilis-Januszewska A, Greaves CJ, Handke U, Pajunen P, Puhl S, Polonen A, Rissanen A, Roden M, Stemper T, Telle-Hjellset V, Tuomilehto J, Velickiene D, Schwarz PE, Acosta T, Adler M, Alkerwi A, Barengo N, Barengo R, Boavida JM, Charlesworth K, Christov V, Claussen B, Cos X, Cosson E, Deceukelier S, Dimitrijevic-Sreckovic V, Djordjevic $P$, et al: Take action to prevent diabetes-the IMAGE toolkit for the prevention of type 2 diabetes in Europe. Horm Metab Res 2010, 42:S37-S55.

18. Schwarz PE, Greaves CJ, Lindstrom J, Yates T, Davies MJ: Nonpharmacological interventions for the prevention of type 2 diabetes mellitus. Nat Rev Endocrinol 2012, 8:363-373.

19. Gorbach SL: Probiotics and gastrointestinal health. Am J Gastroenterol 2000, 95:S2-S4.

20. Liu Q, Duan ZP, Ha DK, Bengmark S, Kurtovic J, Riordan SM: Synbiotic modulation of gut flora: effect on minimal hepatic encephalopathy in patients with cirrhosis. Hepatology 2004, 39:1441-1449.

21. Chiva M, Soriano G: Effect of Lactobacillus jhonsonii La1 and antioxidants on intestinal flora and bacterial translocation in a rat model of experimental cirrhosis. J Hepatol 2000, 36:501-506.

22. Allen SJ, Martinez EG, Gregorio GV, Dans LF: Probiotics for treating acute infectious diarrhoea [review]. Cochrane Database Syst Rev 2010, 10(11):CD003048.

23. Allen SJ, Okoko B, Martinez EG, Gregorio GV, Dans LF: Probiotics for treating infectious diarrhoea. Cochrane Database Syst Rev 2004, 2:CD003048.

24. Checkley W, Buckley G, Gilman RH, Assis AM, Guerrant RL, Morris SS, Mølbak K, Valentiner-Branth P, Lanata CF, Black RE: Childhood malnutrition and infection network. Multi-country analysis of the effects of diarrhoea on childhood stunting. Int J Epidemiol 2008, 37:816-830.

25. Johnston BC, Supina AL, Ospina M, Vohra S: Probiotics for the prevention of pediatric antibiotic-associated diarrhoea. Cochrane Database Syst Rev 2007, 2:CD004827.

26. Szajewska H, Mrukowicz JZ: Probiotics in the treatment and prevention of acute infectious diarrhoea in infants and children: a systematic review of published randomized, double-blind, placebo-controlled trials. J Pediatr Gastroenterol Nutr 2001, 33:S17-S25.

27. Cremonini F, Di Caro S, Nista EC, Bartolozzi F, Capelli G, Gasbarrini G, Gasbarrini A: Meta-analysis: the effect of probiotic administration on antibiotic-associated diarrhoea. Aliment Pharmacol Ther 2002, $16: 1461-1467$

28. Huang JS, Bousvaros A, Lee JW, Diaz A, Davidson EJ: Efficacy of probiotic use in acute diarrhoea in children: a meta-analysis. Dig Dis Sci 2002, 47:2625-2634.

29. Sazawal S, Hiremath G, Dhingra U, Malik P, Deb S, Black RE: Efficacy of probiotics in prevention of acute diarrhoea: a meta-analysis of masked, randomised, placebo-controlled trials. Lancet Infect Dis 2006, 6:374-382.

30. Van Niel CW, Feudtner C, Garrison MM, Christakis DA: Lactobacillus therapy for acute infectious diarrhoea in children: a meta-analysis. Pediatrics 2002 109:678-684.

31. Fang SB, Lee HC, Hu JJ, Hou SY, Liu HL, Fang HW: Dose-dependent effect of Lactobacillus rhamnosus on quantitative reduction of faecal rotavirus shedding in children. J Trop Pediatr 2009, 55:297-301.

32. Guandalini S, Pensabene L, Zikri MA, Dias JA, Casali LG, Hoekstra H, Kolacek S, Massar K, Micetic-Turk D, Papadopoulou A, de Sousa JS, Sandhu B, Szajewska H, Weizman Z: Lactobacillus GG administered in oral rehydration solution to children with acute diarrhea: a multicenter European trial. J Pediatr Gastroenterol Nutr 2000, 30:54-60.

33. Henker J, Laass M, Blokhin BM, Bolbot YK, Maydannik VG, Elze M, Wolff C, Schulze J: The probiotic Escherichia coli strain Nissle 1917 (EcN) stops acute diarrhoea in infants and toddlers. Eur J Pediatr 2007, 166:311-318.

34. Moayyedi P, Ford AC, Brandt LJ, Foxx-Orenstein AE, Cremonini F, Talley NJ, Cremonini F, Foxx-Orenstein AE, Brandt $L$, Quigley EM: The efficacy of probiotics in the treatment of irritable bowel syndrome: a systematic review. Gut 2010, 59:325-332.

35. Whorwell PJ, Altringer L, Morel J, Bond Y, Charbonneau D, O'Mahony L, Kiely B, Shanahan F, Quigley EM: Efficacy of an encapsulated probiotic Bifidobacterium infantis 35624 in women with irritable bowel syndrome. Am J Gastroenterol 2006, 101:1581-1590.

36. Turnbaugh PJ, Hamady M, Yatsunenko T, Cantarel BL, Duncan A, Ley RE, Sogin ML, Jones WJ, Roe BA, Affourtit JP, Egholm M, Henrissat B, Heath AC Knight R, Gordon J: A core gut microbiome in obese and lean twins. Nature 2009, 457:480-484.

37. Ley RE, Backhed F, Turnbaugh P, Lozupone CA, Knight RD, Gordon J: Obesity alters gut microbial ecology. Proc Natl Acad Sci U S A 2005, 102:11070-11075.

38. Ley RE, Turnbaugh PJ, Klein S, Gordon J: Microbial ecology: human gut microbes associated with obesity. Nature 2006, 444:1022-1023.

39. Musso G, Gambino R, Cassader M: Interactions between gut microbiota and host metabolism predisposing to obesity and diabetes. Annu Rev Med 2011, 62:361-380.

40. Kootte RS, Vrieze A, Holleman F, Dallinga-Thie GM, Zoetendal EG, de Vos WM, Groen AK, Hoekstra JB, Stroes ES, Nieudrop M: The therapeutic potential of manipulating gut microbiota in obesity and type 2 diabetes mellitus. Diabetes Obes Metab 2012, 14:112-120.

41. Vrieze A, Holleman F, Zoetendal EG, de Vos WM, Hoekstra JB, Nieuwdorp M: The environment within: how gut microbiota may influence metabolism and body composition. Diabetologia 2010, 53:606-613.

42. Diamant M, Blaak EE, de Vos WM: Do nutrient-gut-microbiota interactions play a role in human obesity, insulin resistance and type 2 diabetes? Obes Rev 2011, 12:272-281.

43. Esteve E, Ricart W, Fernandez-Real JM: Gut microbiota interactions with obesity, insulin resistance and type 2 diabetes: did gut microbiota coevolve with insulin resistance? Curr Opin Clin Nutr Metab Care 2011 14:483-490.

44. Timmerman HM, Koning CJ, Mulder L, Rombouts FM, Beynen AC: Monostrain, multistrain and multispecies probiotics-A comparison of functionality and efficacy. Int J Food Microbio/ 2004, 96:219-233.

45. Chapman CM, Gibson GR, Rowland I: Health benefits of probiotics: are mixtures more effective than single strains? Eur J Nutr 2011, 50:1-17.

46. Hildebrandt MA, Hoffmann C, Sherrill-Mix SA, Keilbaugh SA, Hamady M, Chen YY, Knight R, Ahima RS, Bushman F, Wu GD: High-fat diet determines the composition of the murine gut microbiome independently of obesity. Gastroenterology 2009, 137:1716-1724.

47. Niers LE, Timmerman HM, Rijkers GT, van Bleek GM, van Uden NO, Knol EF, Kapsenberg ML, Jimpen $J$, Hoekstra MO: Identification of strong 
interleukin-10 inducing lactic acid bacteria which down-regulate T helper type 2 cytokines. Clin Exp Allergy 2005, 35:1481-1489.

48. Groschwitz KR, Hogan SP: Intestinal barrier function: molecular regulation and disease pathogenesis. J Allergy Clin Immunol 2009, 124:3-20. quiz 1-2.

49. Lutgendorff F: Defending the barrier. Universiteit utrecht; 2009:396.

50. Ly NP, Litonjua A, Gold DR, Celedón JC: Gut microbiota, probiotics, and vitamin D: interrelated exposures influencing allergy, asthma, and obesity? J Allergy Clin Immunol 2011, 127:1087-1094.

doi:10.1186/1745-6215-14-195

Cite this article as: Alokail et al.: Effects of probiotics in patients with

diabetes mellitus type 2: study protocol for a randomized, double-blind,

placebo-controlled trial. Trials 2013 14:195.

\section{Submit your next manuscript to BioMed Central and take full advantage of:}

- Convenient online submission

- Thorough peer review

- No space constraints or color figure charges

- Immediate publication on acceptance

- Inclusion in PubMed, CAS, Scopus and Google Scholar

- Research which is freely available for redistribution 